\title{
EFFECTS OF THE ASPHALT PENETRATION GRADE AND THE MINERALOGICAL COMPOSITION ON THE ASPHALT-AGGREGATE BOND \\ A.R. Pasandin ${ }^{*}$ and I. Pérez \\ Universidade da Coruña. E. T. S. I. Caminos, Canales y Puertos. Campus de Elviña s/n, 15071 A Coruña, Spain \\ "Corresponding author: tel.: +34-981167000. Fax: +34-981167170 \\ E-mail addresses: arodriguezpa@udc.es (A.R.Pasandín),iperez@udc.es (I. Pérez)
}

\begin{abstract}
This investigation analyses the loss of bonding between the asphalt binder and the aggregate particles produced by water in hot-mix asphalt pavements. Three asphalt penetration grades were used: B35/50, B50/70 and B160/220. Four different types of aggregates were chosen due to their different expected stripping performances: hornfels, feldspathic schist, gabbro and dolomitic calcite. To research the loss of adhesion, two laboratory test methods were compared: the rolling bottle method and the boiling water test. The results indicate that a higher asphalt-aggregate bond correlates to a lower asphalt penetration grade. To achieve significant asphalt-aggregate bond improvement, the difference between asphalt penetration grades must be noticeable.

Keywords: asphalt, penetration grade, aggregates, adhesion, bond.

\section{Introduction}

Hot-mix asphalt (HMA) is a construction material that is widely used for flexible pavement roads. Nevertheless, this material presents a serious problem: its tendency to degrade in the presence of water.

As shown in figure 1, HMA is formed by aggregates of different sizes that must be completely coated by the mastic, that is, a mixture of asphalt and filler (mineral powder). When HMA is in service, water can interact in the liquid state or in the form of water vapour (Caro et al., 2008), leading to a loss of bonding between asphalt and aggregate and/or a lack of cohesion of the mastic (Kiggundu and Roberts, 1988). In
\end{abstract}


particular, the loss of bonding may result in the appearance of many types of pavement distresses in HMA layers, such as "stripping" (figure 2), which result in a loss of comfort and traffic safety, as well as a reduction in pavement service life. For all of these reasons, achieving a good adhesion between aggregate and asphalt is very important in the implementation of HMA road pavements.

There are many factors that could affect the adhesion between the aggregate and the asphalt binder in HMA. For example, asphalt properties play a crucial role, especially viscosity and thermal susceptibility. On the one hand, there are studies that demonstrate that the use of high viscosity asphalt improves the performance of HMA against stripping (Abo-Qudais, 2005). This improved performance is mainly due to the higher concentration of polar molecules that is associated with a high asphalt viscosity (Bagampadde, 2004). For this reason, when a mixture is in service, a higher asphalt viscosity leads to a better water resistance (Bagampadde, 2004). On the other hand, during mixing plant operations, it is preferable to use low-viscosity binders because high viscosities (generally with lower asphalt penetration grades) are associated with a poor aggregate coating by the asphalt binder (Bagampade, 2004).

Additionally, the aggregate properties are of particular importance to the adhesion. As a result, it is essential to understand both the chemical and the mineralogical composition. It is generally accepted that siliceous aggregates are hydrophilic (tend to form bonds with water molecules, thus displacing the asphalt); while limestone aggregates are hydrophobic. This last type of aggregate exhibits a greater stripping resistance than hydrophilic aggregates, with some exceptions (Hicks, 1991). 
The aim of the research is to analyse the effect of the asphalt penetration grade on the asphalt-aggregate bond. To generalise the findings, the investigation has been conducted using four types of aggregates, with different expected stripping performances. To perform the research, two types of laboratory tests were chosen due to their rapidity and simplicity (Jo et al., 1997): the rolling bottle method (AENOR, 2011) and the boiling water test (ASTM, 2005).

\section{Materials and methods}

\subsection{Materials characterisation}

\subsubsection{Aggregates}

As stated above, the laboratory evaluation was conducted with four aggregates: hornfels, feldspathic schist, gabbro and dolomitic calcite. All of the aggregates, which are typically used in road construction in Spain, were supplied by local contractors. An X-ray fluorescence spectroscopy (XRF) (Bruker S4 Pioneer Fluorescence Spectrometer) was used to determine the elemental composition of the aggregates. Table 1 describes the main mineralogical composition of the aggregates $\left(\mathrm{SiO}_{2}\right.$ and $\left.\mathrm{CaO}\right)$ according to the X-ray fluorescence test and its bulk specific density $\left(\rho_{\mathrm{a}}\right)$ measured using the saturated surface dry (SSD) water displacement method following UNE EN 1097-6 (AENOR, 2001). As was expected, three of the four selected aggregates (hornfels, feldspathic schist and gabbro) are predominantly siliceous and thus, poor adhesion with the asphalt is expected. Moreover, these three aggregates exhibit different silica $\left(\mathrm{SiO}_{2}\right)$ percentages. A priori, it is assumed that the aggregate which has higher silica content (feldspathic schist) will exhibit poorer adhesion with asphalt. The fourth aggregate (dolomitic calcite) is a mainly limestone aggregate; as a result, it is expected that its affinity with the asphalt and, therefore, its water resistance, should be good. 


\subsubsection{Binder}

B35/50, B50/70 and B160/220 asphalt penetration grades from Venezuela were used in this investigation. The engineering and rheological properties of the asphalts are presented in table 2.

\subsection{Testing program}

As mentioned above, to perform the asphalt-aggregate adhesion analysis, two tests results were compared: the rolling bottle method and the boiling water test. The rolling bottle method was performed according to UNE-EN 12697-11. The test consists of introducing a sample of loose mixture in a bottle with distilled water and letting it rotate. The percentage of asphalt that remains adhered to the aggregate, i.e., that has not been removed as a result of rotation of the bottle, is estimated. This test has no requirements for asphalt coverage; thus, the results are useful for a comparison between samples.

The boiling water test procedure was performed according to the ASTM D3625 test method for mixtures that are not compact (loose mixtures). In this test, a sample of a loose mixture is heated to boil for 10 minutes. Then, the percentage of aggregate that is covered by asphalt, i.e., that has not been detached as the result of the action of boiling water, is determined. A minimum of $85 \%-90 \%$ of asphalt coverage is required in this test to determine if the adhesion between aggregates and asphalt is satisfactory (Kiggundu and Roberts, 1988).

\section{Test results and discussion}

A total of twenty-four mixtures were studied following the laboratory methods described above. As shown in figure 3, the rolling bottle method and the boiling water test results indicate that, as was expected, in general, the use of higher asphalt 
penetration grades leads to worse coating of the aggregates. Thus, the higher the penetration grades are, the worse are the adhesion results. In this regard, both tests, the rolling bottle method and boiling water test, provide the same conclusion. Nevertheless, note that the coverage differences obtained using the three tested asphalts were not very strong.

Moreover, as expected, the results of the rolling bottle method (figure 3a) indicate that the siliceous aggregates (hornfels, feldspathic schist and gabbro) provide adhesion results that were worse than those obtained for the limestone aggregate (dolomitic calcite).

Curiously, the boiling water test results (figure $3 \mathrm{~b}$ ) do not provide the same conclusion because there is an exception: the feldspathic schist (siliceous aggregate) offers similar or even better coating results to those obtained for the dolomitic calcite (limestone aggregate). In fact, the feldspathic schist is the only aggregate that, with asphalt B35/50 and $\mathrm{B} 50 / 70$, achieves the minimum coating requirement of $85 \%$. Two two-way ANOVA analyses were performed using SPSS software (PASW Statistics 18) to determine the effects of the asphalt penetration grade and the type of aggregate on the adhesion between asphalt and aggregate. The asphalt coverage was the dependent variable in each case. For the two ANOVA analyses, the two factors determined were the asphalt penetration grade (B35/50, 50/70 and B160/220) and the type of aggregate (hornfels, feldspathic schist, gabbro and dolomitic calcite). The asphalt coverage is a quantitative variable, while the asphalt penetration grade and the type of aggregate are qualitative variables. 
The ANOVA analysis results are included in table 3. The statistical analysis indicated that, from a statistical point of view, the asphalt penetration grade and the aggregate type affect significantly $(\mathrm{p} \leq 0.05)$ the asphalt-aggregate adhesion.

To refine the results, a Tukey post hoc analysis was also conducted. As shown in table 4a, the rolling bottle method results indicate that the differences between the limestone aggregate (dolomitic calcite) and the siliceous aggregates results are statistically significant in the three cases $(\mathrm{p} \leq 0.0001)$. The results of the boiling water test (table $4 \mathrm{~b}$ ) also indicate that there are statistically significant differences between the limestone aggregate coverage result and the siliceous hornfels and gabbro aggregates coverage results $(\mathrm{p} \leq 0.005)$. On the contrary, there is not statistically significant difference in the coating result $(\mathrm{p}=0.971>0.05)$ between dolomitic calcite and feldspathic schist. This analysis indicates that the aggregate mineralogical composition, i.e., limestone or siliceous type, definitely influences the asphalt-aggregate bond. Nevertheless, there are other factors that can have a major influence, such as texture, porosity or type of solicitation. For this reason, in the boiling water test, in which the bitumen is detached from the aggregate as a result of the heating, the existence of higher porosity or tortuous pores is possibly even more influential in the aggregate- asphalt bond than the aggregate mineralogical composition. Thus, because the porosity can help to ensure that the binder is less easily detached from the aggregate surface. Therefore, feldspathic schist, the aggregate with the lower density (table 1) and hence, with the higher porosity, exhibits similar boiling water coverage results to those obtained for the limestone aggregate. However, the rolling bottle method post hoc analysis indicates that there is no statistically significant difference between the B35/50 and B50/70 coating results ( $\mathrm{p}=$ $0.483>0.05)$, but in the other cases, there are statistically significant differences: 
$\mathrm{B} 35 / 50$ versus $\mathrm{B} 160 / 220(\mathrm{p}=0.006 \leq 0.05)$ and $\mathrm{B} 50 / 70$ versus $\mathrm{B} 160 / 220(\mathrm{p}=0.024 \leq$ 0.05) (Table 4a). In contrast, the boiling water test results indicate that there is only a statistically significant difference between the coating results produced by B35/50 bitumen and B160/220 bitumen ( $\mathrm{p}=0.010 \leq 0.05)$ (Table $4 \mathrm{~b})$. That is, the asphalt penetration grade influences the asphalt-aggregate bond. Nevertheless, when the asphalt-aggregate bond improvement justifies the selection of a lower asphalt penetration grade, the difference between the penetrations must be noticeable.

\section{Conclusions}

Based on the results of this research, the following conclusions can be drawn:

- As was expected, the results of the literature review are confirmed: in general, a higher asphalt penetration grade correlates to a lower asphalt-aggregate bond.

- Nevertheless, to achieve strong asphalt-aggregate bond differences by using different asphalt penetration grades, the difference between the penetration grades must also be noticeable (for example B35/50 versus B160/220).

Otherwise, the adhesion results will not be significant.

- Additionally, as was expected, other literature review conclusions were confirmed: in general, siliceous aggregates exhibit worse adhesion with asphalt than do the limestone aggregates.

- Nevertheless, an important issue must be considered: in addition to the aggregate mineralogical composition, there are other aggregate factors that can even further influence the asphalt-aggregate bond, in particular, the porosity. In this way, a higher porosity leads to a more difficult asphalt detachment from aggregate, especially when the detachment is produced by high temperature. 


\section{Acknowledgements}

The authors acknowledge the Spanish Ministry of Education and Science for sponsoring this research through Project BIA2010-17751.

The authors thank Nynas bitumen for supplying the binder.

The authors thank the Unidade de Análisis Estructural (UAE) of the Universidade da Coruña (UDC) for performing of X-ray fluorescence tests.

\section{References}

Abo-Qudais, S. and Mulqi, M.W. (2005). New Chemical Antistripping Additives for Bituminous Mixtures. Journal of ASTM International 2.8: 87-97.

AENOR (2001). UNE-EN 1097-6:2001. "Determinación de la densidad de partículas y absorción de agua".

AENOR (2011). UNE-EN 12697-11. "Métodos de ensayo para mezclas bituminosas en caliente. Parte 11: Determinación de la afinidad entre áridos y betún”. ASTM “D 3625-96 (2005). Standard Practice for Effect of Water on BituminousCoated Aggregate Using Boiling Water”.

Bagampadde, U. (2004). On investigation of stripping in bituminous mixtures. Licentiate thesis, submitted to the Royal Institute of Technology, Stockholm, Sweden. Caro, S, Masad, E., Bhasin, A. and Little, D.N. (2008). Moisture susceptibility of asphalt mixtures, Part 1: mechanisms. International Journal of Pavement Engineering 9.2: 81-88.

Jo, Myung-Chan, Tarrer, Arthur R., Jeon, Young W., Park, Sang Joon and Yoon, Hyon Hee (1997). Investigation of the effect of aggregate pretreatment with antistripping agents on the asphalt-aggregate bond. Petroleum Science and Technology 15:3-4: 245271. 
Hicks, R.G. (1991). Moisture damage in asphalt concrete. Transportation Research Board 175

Kiggundu, B.M. and Roberts, F.L. (1988). Stripping in HMA mixtures: state-of-the-art and critical review of test methods. NCAT Report 88-02. 
Table 1

Bulk composition in weight of the aggregates according to X-ray fluorescence results

\begin{tabular}{l}
\hline Aggregate \\
\hline Hornfels \\
Feldspathic schist \\
Gabbro \\
Dolomitic calcite
\end{tabular}

Table 2

Rheological and physical properties of asphalt cement.

\begin{tabular}{|l|l|c|c|c|}
\hline Test & Standard & B35/50 & B50/70 & B160/220 \\
\hline Original & \multicolumn{2}{|l|}{} \\
\hline $\begin{array}{l}\text { Penetration }(100 \mathrm{~g}, 5 \mathrm{~s}, \\
\left.25^{\circ} \mathrm{C}\right), 0.1 \mathrm{~mm}\end{array}$ & $\begin{array}{l}\text { UNE-EN } \\
1426\end{array}$ & 38 & 52 & $50-70$ \\
\hline Softening point, ${ }^{\circ} \mathrm{C}$ & $\begin{array}{l}\text { UNE-EN } \\
1427\end{array}$ & 59.5 & 54.9 & $48-57$ \\
\hline Flash Point, ${ }^{\circ} \mathrm{C}$ & ISO 2592 & 298 & $>290$ & $>235$ \\
\hline Density $\left(25^{\circ} \mathrm{C}\right), \mathrm{g} / \mathrm{cm}^{3}$ & NLT-122 & 1.023 & 1.009 & $>1.0$ \\
\hline $\begin{array}{l}\text { After thin film } \\
\left.25^{\circ} \mathrm{C}\right), 0.1 \mathrm{~mm}\end{array}$ & 83 & 68 & $>50$ \\
\hline$\Delta$ Softening point, ${ }^{\circ} \mathrm{C}$ & NLT-124 & 5 & 6.5 & $<9$ \\
\hline
\end{tabular}

Table 3

ANOVA results indicating the effects of the asphalt penetration grade and the type of aggregate on the adhesion between asphalt and aggregate using a) the rolling bottle method and b) the boiling water test.

a) Rolling bottle method

\begin{tabular}{llllll}
\multicolumn{1}{c}{ Source of Variation } & \multicolumn{1}{c}{ SS $(*)$} & DF $(*)$ & MS $(*)$ & F $(*)$ & p-value \\
\hline MAIN EFFECTS & & & & & \\
\hline A: Aggregate type & $1,956.25$ & 3 & 652.08 & 78.25 & $<0.0001$ \\
\hline B: Penetration grade & 216.67 & 2 & 108.33 & 13.00 & 0.007 \\
\hline RESIDUAL & 50.00 & 6 & 8.33 & & \\
\hline TOTAL & $2,222.92$ & 11 & & &
\end{tabular}

b) Boiling water test

\begin{tabular}{lccccc}
\multicolumn{1}{r}{ Source of Variation } & SS $(*)$ & DF $(*)$ & MS $(*)$ & F $(*)$ & p-value \\
\hline MAIN EFFECTS & & & & & \\
\hline A: Aggregate type & $6,372.99$ & 3 & $2,124.31$ & 26.37 & 0.001 \\
\hline B: Penetration grade & $1,516.67$ & 2 & 758.33 & 9.41 & 0.014 \\
\hline RESIDUAL & 483.33 & 6 & 80.56 & & \\
\hline TOTAL & $8.372,92$ & 11 & & &
\end{tabular}

(*) SS: sum of squares; DF: degrees of freedom and MS: mean square 
Table 4

Tukey post hoc results indicating the effects of the asphalt penetration grade and the type of aggregate on the adhesion between asphalt and aggregate using a) the rolling bottle method and $b$ ) the boiling water test.

a) Rolling bottle method

\begin{tabular}{c|c|c}
\multicolumn{2}{c|}{ Aggregate } & $\mathrm{p}$-value \\
\hline \multirow{4}{*}{ Hornfels } & Schist & 0.891 \\
\cline { 2 - 3 } & Gabbro & 1.000 \\
\cline { 2 - 3 } Schist & Calcite & $\mathrm{p}<0.0001$ \\
\hline & Hornfels & 0.891 \\
\cline { 2 - 3 } & Gabbro & 0.891 \\
\hline \multirow{4}{*}{ Gabbro } & Calcite & $\mathrm{p}<0.0001$ \\
\cline { 2 - 3 } & Hornfels & 1.000 \\
\cline { 2 - 3 } & Schist & 0.891 \\
\hline \multirow{3}{*}{ Calcite } & Calcite & $\mathrm{p}<0.0001$ \\
\cline { 2 - 3 } & Hornfels & $\mathrm{p}<0.0001$ \\
\cline { 2 - 3 } & Schist & $\mathrm{p}<0.0001$ \\
\hline \multirow{2}{*}{ Penetration grade } & $\mathrm{p}<0.0001$ \\
\hline \multirow{2}{*}{ B35/50 } & B50bbro & $\mathrm{p}$-value \\
\cline { 2 - 3 } & B160/220 & 0.483 \\
\hline \multirow{2}{*}{ B50/70 } & B35/50 & 0.006 \\
\cline { 2 - 3 } & B160/220 & 0.483 \\
\hline \multirow{2}{*}{ B160/220 } & B35/50 & 0.024 \\
\cline { 2 - 3 } & B50/70 & 0.006 \\
\hline
\end{tabular}

b) Boiling water test

\begin{tabular}{c|c|c}
\multicolumn{2}{c|}{ Aggregate } & p-value \\
\hline \multirow{3}{*}{ Hornfels } & Schist & 0.001 \\
\cline { 2 - 3 } & Gabbro & 0.157 \\
\cline { 2 - 3 } Schist & Calcite & 0.002 \\
\hline \multirow{3}{*}{ Gabbro } & Hornfels & 0.001 \\
\cline { 2 - 3 } & Gabbro & 0.010 \\
\hline & Calcite & 0.966 \\
\cline { 2 - 3 } & Hornfels & 0.157 \\
\cline { 2 - 3 } & Schist & 0.010 \\
\hline \multirow{4}{*}{ Calcite } & Calcite & 0.015 \\
\cline { 2 - 3 } & Hornfels & 0.002 \\
\cline { 2 - 3 } & Schist & 0.966 \\
\hline \multirow{2}{*}{ Penetration grade } & 0.015 \\
\hline \multirow{2}{*}{ B55/50 } & B50bbro & p-value \\
\cline { 2 - 3 } & B160/220 & 0.200 \\
\hline \multirow{2}{*}{ B160/220 } & B35/50 & 0.012 \\
\cline { 2 - 3 } & B160/220 & 0.200 \\
\cline { 2 - 3 } & B35/50 & 0.121 \\
\hline & B50/70 & 0.012 \\
\hline
\end{tabular}


Figure 1

Section of HMA cylindrical specimen.

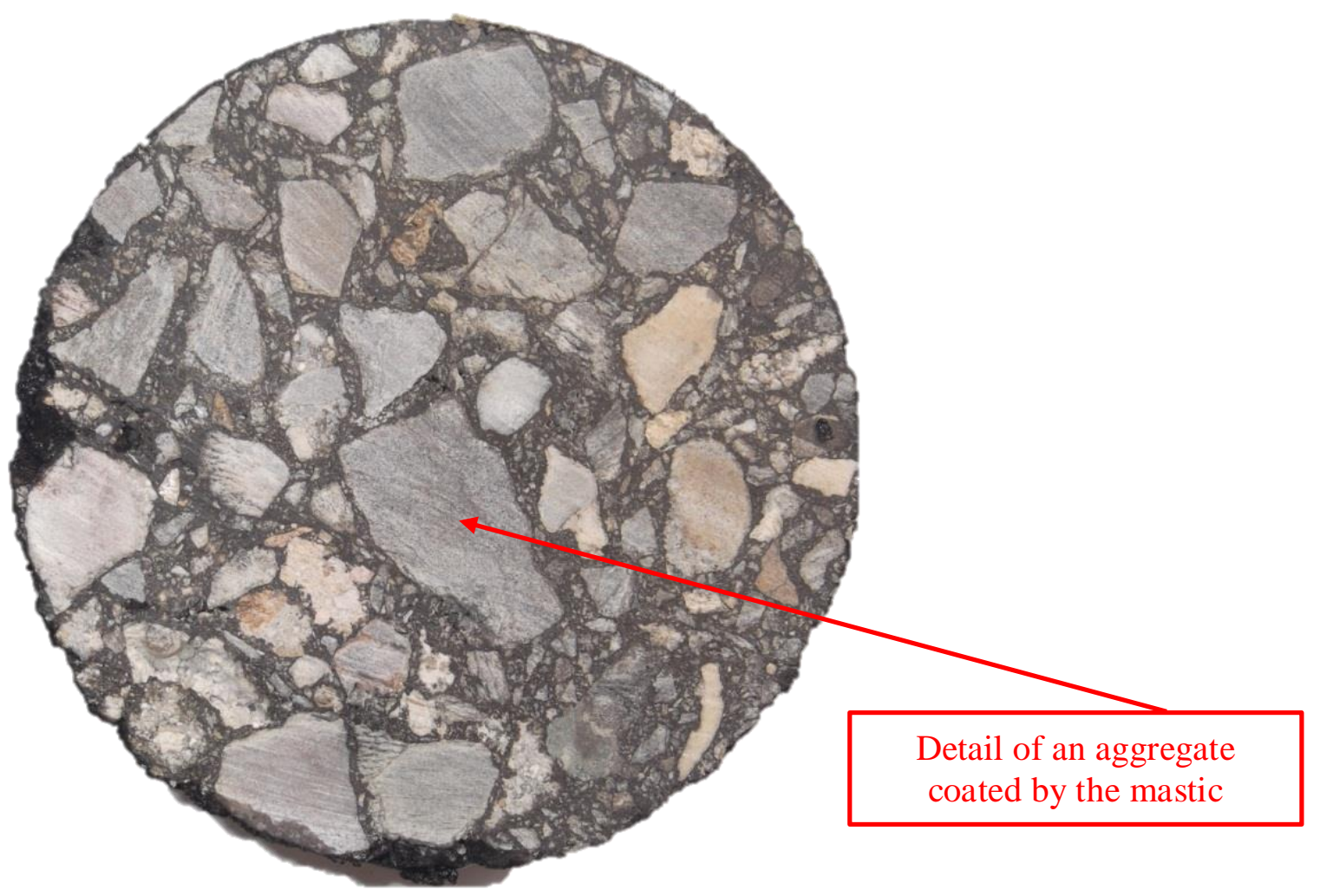

Figure 2

Flexible pavement distress due to the action of water.

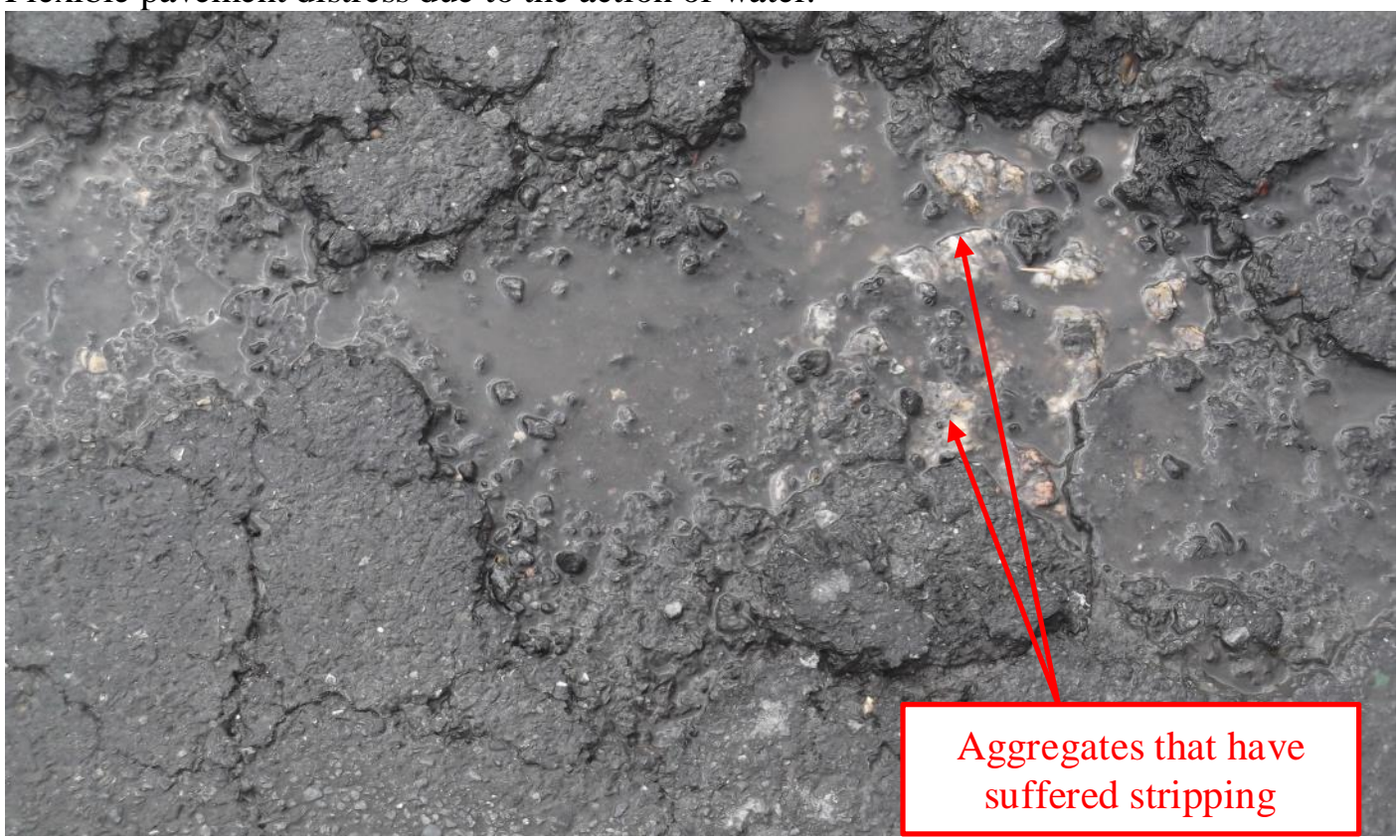


Figure 3

Adhesion between asphalt and aggregate results: a) the rolling bottle method and b) boiling water test.

a) Rolling bottle method

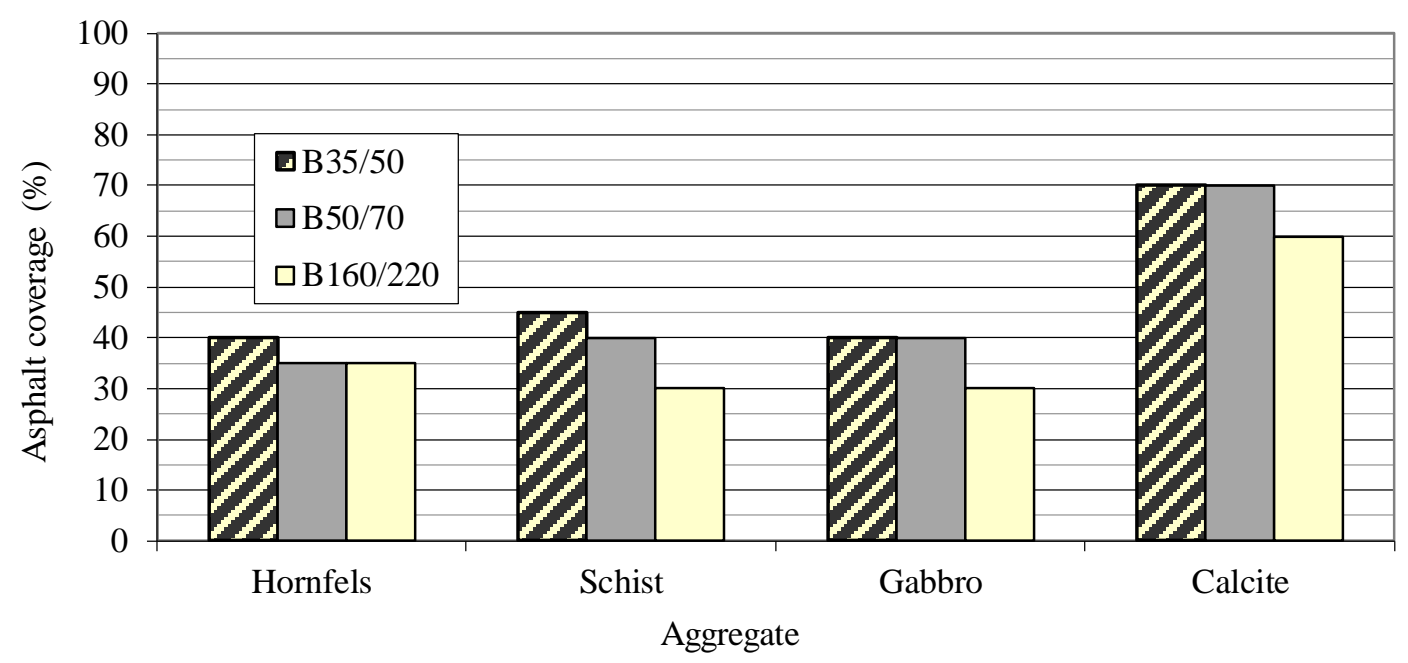

b) Boiling water test

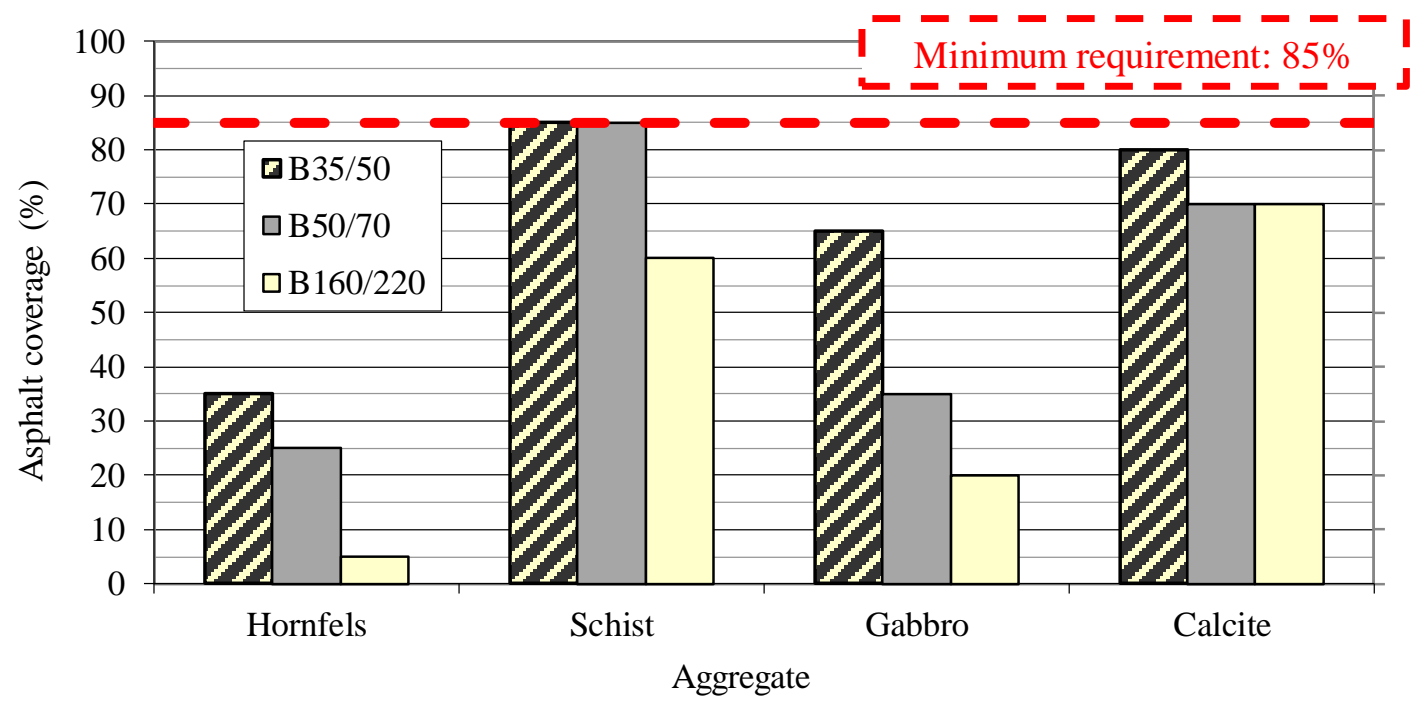

